\title{
nature
}

\section{Cultural divides, forty years on}

A famous lecture given in 1959 still resonates. Although time has eroded many of the cultural fis sures that it addressed, current debates about biotechnology highlight continuing problems of mutual incomprehension.

$\mathrm{N}$ o one can now complain, as C. P. Snow did 40 years ago in his lecture The Two Cultures, of a lack of assimilation of science by the arts. There is now too much success in the form of plays, novels, poetry and paintings that have been infused with science, and have wide appeal, for that basic concern to be sustained.

But Snow's worries about a divided culture were of much broader scope. His starting point was that the "traditional" literary culture not only failed to understand science, but was also too dominant. "Scientists have the future in their bones, traditional culture responds by wishing that the future does not exist. It is the traditional culture ... which manages the western world." However accurate his portrayal then, society's hierarchy has moved on. Few Western administrations and governments suffer fundamentally from a lack of scientific and technological perspective, or from another sin that he highlighted, a lack of serious interest in engineering and business.

Snow placed great faith in an improved balance of education as the critical way forward. The fact that surveys of the public continue to display a worryingly low level of knowledge of scientific facts, or comprehension of the scientific process, suggests that undoubted progress in lessening cultural divides has been as much due to other factors.

Here, scientists willing to communicate widely, science writers and publishers should take their bow. Alongside the quality media, one can celebrate books like Lucy (written by Donald Johanson), which conveys not only the excitement of palaeontology but also its cautious thoroughness; like Nobel Dreams (Gary Taubes), which illuminates the influence of personality in the practice of particle physics; like Guns, Germs and Steel (Jared Diamond), which highlights what science can contribute to understanding 13,000 years of human history - these as well as the cornucopia of more explanatory texts on genetics, evolution, cosmology and quantum physics can take their share of the credit. And if novels such as Mendel's Dwarf (Simon Mawer) and plays such as Copenhagen (Michael Frayn) not only assimilate science but explicitly explore issues that it raises, so much the better for cultural bridge building.

\section{Dis parity}

There is one point where Snow turned out to be mistaken: his prediction that, once it was clear how "rather easy" it is to take up technology, the poor nations of the world would refuse to sit still and, using whatever aid they could obtain, would catch up. "The disparity between rich and poor has been noticed ... Whatever else lasts until 2000, that won't." But how would the gap be removed, and by whom? Large amounts of capital, Snow said, must come from outside, by way of national efforts. An immense investment of capital and scientists into poor countries by the West, with negligible rewards in the short term and uncertain benefits in the long: Snow acknowledged that this was politically daunting but believed it essential. The political and economic reasons why Snow's prediction proved wrong sound a warning against optimistic technocratic naivety.

But there is a sharp end of public controversy about technologies where principles and vested interests are at stake, where science is uncertain, where public confidence is even more uncertain, and where Snow's concerns about scientific incomprehension and, for that mat- ter, about non-developed nations, are as relevant as ever. Nowhere has this been more vividly displayed than in debates about the use of genetically modified organisms, especially in Europe and parts of the developing world. "...total incomprehension gives, much more pervasively than we realise, living in it, an unscientific flavour to the whole culture, and that unscientific flavour is often, much more often than we admit, on the point of turning anti-scientific..." So said Snow then, but in this current debate a general lack of scientific understanding is not the critical cause for concern. Moreover, the essentials of the relevant science are relatively easy to communicate. The more significant obstacles to a respectable quality of debate are cultural: the culture of the scientific community, and the culture within which such public controversies arise.

\section{Challenges}

Opponents of agricultural biotechnology have several things going for them: principles (such as belief in the virtues of a 'natural' approach) and a capacity to organize and to lobby (an operational coherence undermined when they have government responsibility, as the disarray of the Greens in Germany suggests). Like it or not, they also command a degree of public trust that outweighs that given to government, let alone the biotechnology industry.

In such circumstances, teaching people science does not adequately address the issues. But enhancing public awareness of what science does and doesn't say can at least raise the quality of debate and the wisdom (a quality Snow also explicitly sought in narrowing cultural divides) of the decisions reached. Here, the scientists find themselves at a disadvantage. The gatekeepers in the media (producers, news and features editors) are not the science correspondents, and often have their own sympathies, commercial agendas and incomprehensions which can obstruct the exposure of relevant facts in the midst of headline-grabbing but misleading assertions. Professional scientific bodies have a critical role to play, but in the rapid cycle of daily news they are not geared to supplying a timely and appropriately crafted succession of packaged facts, while governments are reluctant to be perceived to be partisan in coordinating public responses from non-governmental scientists. And industry, too often, is publicly ineffectual.

Here, then, are cultural challenges to scientists and technologists (sometimes hard to distinguish in bioscience) at two levels. One is tactical, where obstacles to spreading the message must be overcome by lobbying that is independent of industry and government, and streetwise with respect to the media and the Internet. Swiss scientists adopted a self-coordinated approach in last year's referendum on the use of genetically modified organisms, and a similar lobbying responsiveness, to other ends, has been achieved by Britain's Save British Science.

There is also the need to bridge divides: to achieve more understanding of objectors' principles at home, and of cultural and societal realities in the developing world, without which novel food technology that may be essential to feed future populations will be insensitively promoted or introduced and fail to be accepted. Many of Snow's original concerns today seem gratifyingly irrelevant in general, but naivety should be avoided where cultural antipathies are very much alive and kicking. 